\title{
Transcutaneous ultrasound assessment of internal thoracic artery to coronary artery grafts in patients with and without ischaemic symptoms
}

\author{
A Mauric, D P de Bono, N J Samani, T J Spyt, T Hartshone, D H Evans
}

\begin{abstract}
Objective-To evaluate transcutaneous duplex ultrasound in the assessment of internal thoracic artery to coronary artery grafts.

Setting-Regional cardiothoracic centre. Methods-Prospective duplex ultrasound evaluation of 83 consecutive patients undergoing left internal thoracic artery to coronary artery grafts, together with combined angiographic and duplex ultrasound evaluation of 17 patients with suspected recurrent myocardial ischaemia after internal thoracic artery grafting.

Results-The grafted internal thoracic artery was imaged in $65(78 \%)$ of 83 consecutive postoperative patients, and in 13 (75\%) of 17 patients with suspected graft dysfunction. Grafts were recognised by their characteristic position and biphasic blood flow pattern. Resting graft flow was estimated from the time averaged velocity and graft cross sectional area. Median resting flow in patients without ischaemic symptoms was $36 \mathrm{ml} / \mathrm{min}$ (interquartile range 24 to $49 \mathrm{ml} / \mathrm{min}$ ). Of 13 patients with recurrent ischaemia in whom the graft could be imaged, nine patients with estimated flow in the lowest quartile or abnormal flow profiles, or both, had graft disease or anastomotic problems on angiography, while four with satisfactory graft flow on ultrasound examination had normal graft flow on angiography, but had evidence of native disease progression in other vessels. Two of four patients in whom it was not possible to image the graft on ultrasound had satisfactory graft function on angiography.

Conclusions-For those patients whose internal thoracic artery graft can be imaged, transcutaneous duplex ultrasound is a helpful non-invasive guide to graft function. The main limitations to the technique are an inability to image the graft in about $20 \%$ of patients, and possible inaccuracy in estimating graft diameter.
\end{abstract}

\section{(Br Heart $\mathcal{f} 1994 ; 72: 476-481)$}

The left internal thoracic artery is now accepted as the conduit of choice for surgical revascularisation of the left anterior descending coronary artery and, with some reservations, other accessible coronary vessels. ${ }^{1-3} \mathrm{We}$ have previously described the use of transcutaneous duplex ultrasound in imaging the proximal part of the grafted internal thoracic artery and have related the estimated graft bloodflow to "runoff" in the graft territory. ${ }^{4-5}$ Several other groups have reported similar or complementary techniques and results. ${ }^{6-8} \mathrm{We}$ report here the range of ultrasound findings in a prospective series of consecutive patients undergoing left internal thoracic artery grafting, and attempt to correlate ultrasound and angiographic findings in patients with suspected recurrent ischaemia after grafting. Our objectives were to define the range of "normality" of ultrasound graft measurements and to identify possible patterns which correlate with graft malfunction.

\section{Patients and methods}

Eighty three consecutive patients operated on by a single surgeon (TJS) were identified from operating lists and invited to attend for outpatient ultrasound assessment. They were interviewed by a doctor to ensure they were free from anginal symptoms. Patients rested supine for at least 20 minutes before examination. Examinations were performed at least two hours after any meal. Patients continued to take their usual drugs on the day of the study. Sixteen patients with 18 internal thoracic artery grafts presenting to our service over the same period with suspected recurrent ischaemia after previous internal thoracic artery grafting underwent a duplex ultrasound examination followed by angiography. Coronary and graft angiography were performed by standard techniques from a femoral approach using 7FG catheters.

The technique of duplex ultrasound assessment was as previously described..$^{4-5} \mathrm{~A}$ Diasonics (Bedford, United Kingdom) ultrasound system (Diasonics Spectra) was used with a $5 \mathrm{MHz}$ linear array probe and colourflow Doppler facility. The upper left parasternal and supraclavicular transducer positions were used. The colourflow facility was used to identify the origin of the internal thoracic artery as it arose from the first part of the subclavian artery. The diameter of the vessel was measured with the transducer as near to 
Figure 1 Doppler sonogram of a normally functioning internal thoracic artery to coronary artery bypass graft. There are two velocity peaks in each cycle, one in systole (s) and one in diastole

(d).

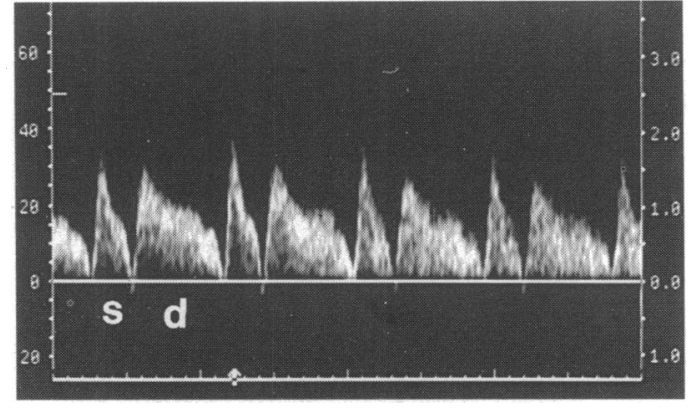

perpendicular to the vessel as possible. Thereafter a transducer position as near coaxial with the vessel as possible was chosen to record the Doppler sonogram. An angle of less than 60 degrees was usually possible even from a parasternal approach. Ultrasound measurements were made using internal software, with appropriate correction for the angle of insonation.

Graft flow is estimated by multiplying the time averaged velocity of blood flow by the cross sectional area of the graft (calculated from graft diameter assuming a circular cross section). Cycle time averaged velocity is the integral of a plot of mean velocity against time over the whole cardiac cycle, divided by the cycle time. We also recorded systolic and diastolic times (derived from the electrocardiogram) and systolic and diastolic peak and average velocities. Data were recorded and analysed using Minitab. Univariate correlations were examined using Pearson's regression coefficient $(\mathbf{r})$.

\section{Results}

ASYMPTOMATIC PATIENTS

The period between the operation and the ultrasound examination of the graft ranged from eight to 583 days, with a median of 217 days and an interquartile range of 157 to 367 days. Figure 1 shows a Doppler sonogram from a grafted internal thoracic artery. The grafted internal thoracic artery was imaged in 65 to 83 patients $(78 \%)$ and in 42 of the last 50 consecutive patients studied $(84 \%)$. The diameter of the internal thoracic artery graft was measured and flow data recorded in 60 patients $(73 \%)$ who did not have ischaemic symptoms at the time of measurement. Table 1 gives these data.

There was a skewed distribution of total resting graft flow, with a median of $36 \mathrm{ml} / \mathrm{min}$ and an interquartile range of $24-49 \mathrm{ml} / \mathrm{min}$. There was no correlation between graft flow and time since the operation $\left(\mathrm{r}^{2}=1 \cdot 86 ; \mathrm{P}=\right.$ $0 \cdot 20)$. Figure 2 shows scatterplots showing the relation of total flow to cycle time averaged velocity, graft diameter, and peak systolic and diastolic velocities. Each of these variables was positively correlated with total graft flow on univariate regression analysis (see legend to fig 2). There was no correlation between graft cross sectional area and cycle time averaged velocity $(r=0.13 ; P=$ 0.57 ) and the two parameters contributed independently to the variability of the estimated flow. There was no correlation between graft flow and length of time since the operation, at least within the time range studied. Twelve patients were studied on two occasions one month apart: $95 \%$ of repeat flow estimates lay within $15 \%$ of the original estimate and there was no significant change in mean flow over this period.

\section{PATIENTS WITH SUSPECTED POSTOPERATIVE} ISCHAEMIA

Ultrasound measurements of grafted internal thoracic artery flow were attempted in 17 patients (19 grafts) with recurrent ischaemic symptoms (table 2). These patients fell into three groups.

GROUP 1

In this group (four patients) the internal thoracic artery graft could not be imaged using duplex ultrasound. Two patients in this group were shown to have patent grafts with normal flow on subsequent angiography, and two had an occluded graft.

\section{GROUP 2}

Graft imaging in these four patients was successful; graft flow was in the upper three quartiles and the qualitative appearance of graft flow was normal with discrete systolic and diastolic velocity peaks. Subsequent

Table 1 Ultrasound measurements of grafted internal thoracic artery flow characteristics and diameter in 60 patients without ischaemic symptoms

\begin{tabular}{|c|c|c|c|c|c|c|}
\hline & Range & Mean & Median & Standard deviation & first quartile & third quartile \\
\hline Rate (/min) & 48-105 & $71 \cdot 0$ & $68 \cdot 5$ & $11 \cdot 8$ & 65 & 76 \\
\hline $\begin{array}{l}\text { Time averaged } \\
\text { velocity }(\mathrm{cm} / \mathrm{s})\end{array}$ & $7 \cdot 0-33 \cdot 0$ & $16 \cdot 3$ & 15 & 6.6 & $11 \cdot 0$ & $19 \cdot 5$ \\
\hline $\begin{array}{l}\text { Peak systolic } \\
\text { velocity }(\mathrm{cm} / \mathrm{s})\end{array}$ & $17 \cdot 0-119 \cdot 0$ & $52 \cdot 4$ & $46 \cdot 0$ & $21 \cdot 9$ & $35 \cdot 0$ & $64 \cdot 8$ \\
\hline $\begin{array}{l}\text { Time averaged } \\
\text { velocity systole } \\
(\mathrm{cm} / \mathrm{s})\end{array}$ & $5 \cdot 0-33 \cdot 0$ & $17 \cdot 5$ & $18 \cdot 0$ & $6 \cdot 55$ & $12 \cdot 0$ & $22 \cdot 0$ \\
\hline $\begin{array}{l}\text { Peak diastolic } \\
\text { velocity }(\mathrm{cm} / \mathrm{s})\end{array}$ & $11 \cdot 0-73 \cdot 0$ & $36 \cdot 4$ & $32 \cdot 5$ & $14 \cdot 5$ & $25 \cdot 0$ & $47 \cdot 8$ \\
\hline $\begin{array}{l}\text { Time averaged } \\
\text { velocity diastole } \\
(\mathrm{cm} / \mathrm{s})\end{array}$ & $6 \cdot 0-30 \cdot 0$ & $15 \cdot 1$ & $13 \cdot 0$ & $6 \cdot 42$ & $10 \cdot 3$ & $19 \cdot 3$ \\
\hline $\begin{array}{l}\text { Peak systolic/ } \\
\text { diastolic velocity } \\
(\mathrm{cm} / \mathrm{s})\end{array}$ & $0 \cdot 88-2 \cdot 75$ & 1.57 & $1 \cdot 61$ & 0.36 & $1 \cdot 32$ & 1.80 \\
\hline $\begin{array}{l}\text { Diameter }(\mathrm{mm}) \\
\text { Flow }(\mathrm{ml} / \mathrm{min})\end{array}$ & $\begin{array}{l}1 \cdot 6-3 \cdot 4 \\
12-95\end{array}$ & $\begin{array}{l}2 \cdot 3 \\
39\end{array}$ & 36 & 22 & 24 & $\begin{array}{l}2 \cdot 4 \\
49\end{array}$ \\
\hline
\end{tabular}



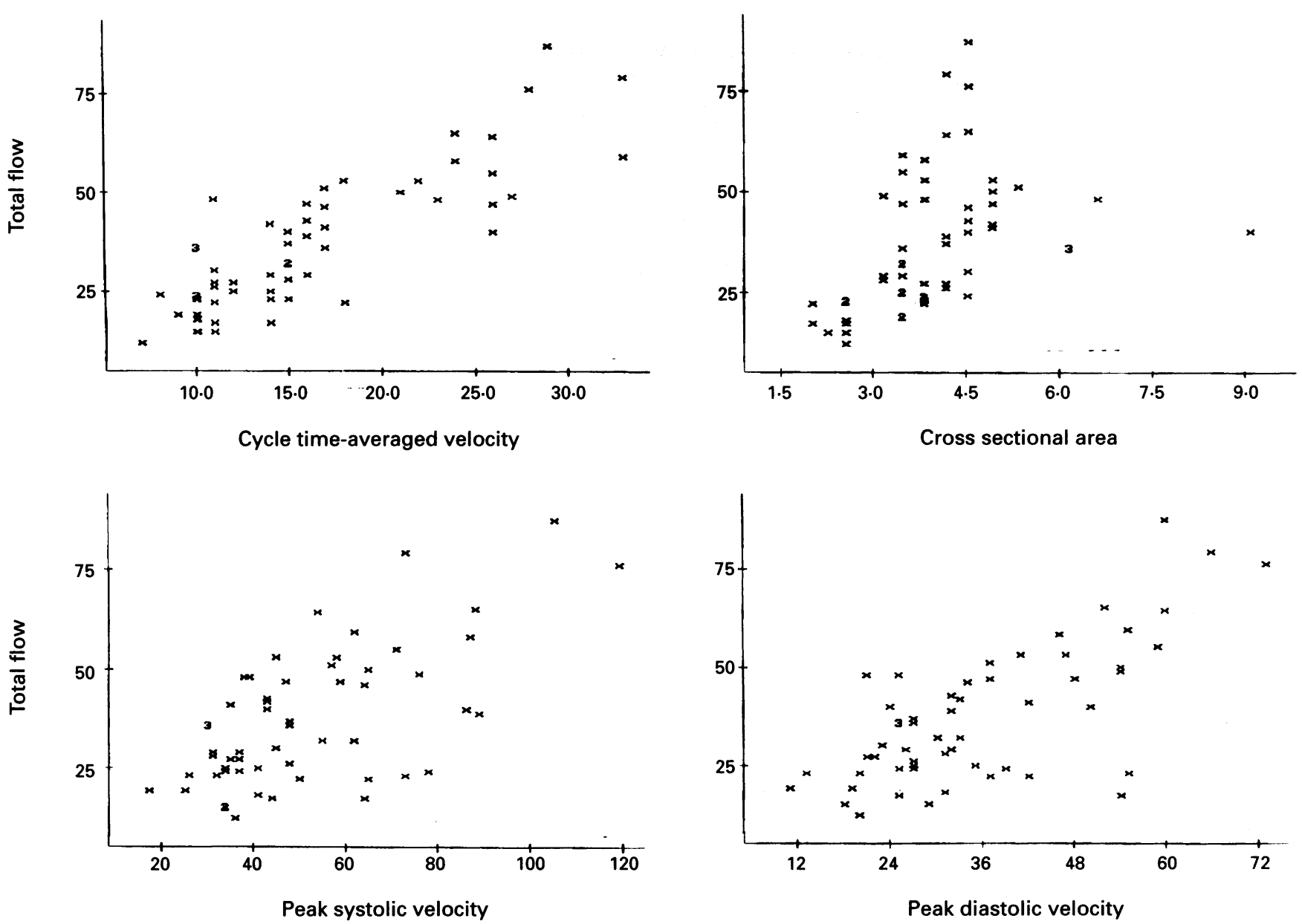

Figure 2 Scatterplots showing the relation of total flow to cycle time averaged velocity (CTAV), graft cross sectional area (CSA), and peak systolic and diastolic velocities. Vertical axis of each plot represents graft flow ( $\mathrm{ml} / \mathrm{min})$. Velocities are in $\mathrm{cm} / \mathrm{s}$; cross sectional area is in $\mathrm{mm}^{2}$. Univariate regression equations were as follows: total flow $=-2 \cdot 78+2 \cdot 57$ CTAV $\left(r^{2}=60 \cdot 4 \%\right)$; total flow $=-7 \cdot 27+11 \cdot 6$ CSA $\left(r^{2}=41 \cdot 4 \%\right) ;$ total flow $=5 \cdot 69+$ $0.65 \times$ peak systolic velocity $\left(r^{2}=38.9 \%\right)$; and total flow $=4.56+0.96 \times$ peak diastolic velocity $\left(r^{2}=39 \cdot 2 \%\right)$.

angiography showed normal flow in these patients, though three of the four had evidence of progression of native vessel disease or disease affecting a graft other than the internal thoracic artery.
GROUP 3

Graft imaging in these nine patients showed flow which was qualitatively abnormal (increased systolic to diastolic velocity ratio) or in the lowest quartile. Subsequent angio-

Table 2 Ultrasound and angiographic findings in patients with postoperative ischaemia

\begin{tabular}{|c|c|c|}
\hline & $\begin{array}{l}\text { Ultrasound } \\
\text { Findings }\end{array}$ & $\begin{array}{l}\text { Angiographic } \\
\text { Findings }\end{array}$ \\
\hline \multicolumn{3}{|c|}{ Group 1: graft not imaged } \\
\hline Patient A & - & Good flow \\
\hline Patient B & - & Poor flow \\
\hline Patient C & - & Occluded \\
\hline Patient D & - & Good flow \\
\hline \multicolumn{3}{|c|}{ Group 2: graft imaged, normal graft flow } \\
\hline Patient E & $34 \mathrm{ml} / \mathrm{min}$ & Good graft, progression of native disease \\
\hline Patient F & $45 \mathrm{ml} / \mathrm{min}$ & Good graft, progression of native disease \\
\hline Patient G & $40 \mathrm{ml} / \mathrm{min}$ & Good graft, no progression \\
\hline Patient $\mathrm{H}$ & $60 \mathrm{ml} / \mathrm{min}$ & Good flow \\
\hline \multicolumn{3}{|c|}{ Group 3: graft imaged, abnormal graft flow } \\
\hline Patient I & See text (case 1) & Occluded graft \\
\hline Patient $\mathrm{J}$ & See text (case 2) & Hypoplastic \\
\hline Patient K & $19 \mathrm{ml} / \mathrm{min}$ & Patent, poor runoff \\
\hline Patient L & $12 \mathrm{ml} / \mathrm{min}$ & Hypoplastic, poor runoff \\
\hline Patient M & $12 \mathrm{ml} / \mathrm{min}$ & Hypoplastic, poor runoff \\
\hline Patient N & $20 \mathrm{ml} / \mathrm{min}$ & $\begin{array}{l}\text { Graft to distal left anterior descending coronary artery: } \\
\text { obstruction to proximal flow }\end{array}$ \\
\hline Patient $\mathrm{O}$ & $\begin{array}{l}\text { (i) Right graft: } 10 \mathrm{ml} / \mathrm{min} \\
\text { (ii) Left graft: } 11 \mathrm{ml} / \mathrm{min}\end{array}$ & $\begin{array}{l}\text { Distal obstruction } \\
\text { Mid-portion obstruction }\end{array}$ \\
\hline Patient $\mathbf{P}$ & $14 \mathrm{ml} / \mathrm{min}$ & Poor runoff \\
\hline Patient Q & Graft seen: poor flow, not measurable & $\begin{array}{l}\text { Small graft, } \\
\text { poor runoff }\end{array}$ \\
\hline Patient R & $\begin{array}{l}\text { (i) Right graft: seen, poor flow, } \\
\text { not measurable } \\
\text { (ii) Left graft: } 34 \mathrm{ml} / \mathrm{min} \\
\text { (iii) Right graft after } \\
\text { percutaneous transluminal coronary } \\
\text { angioplasty; (six months) } \\
\mathbf{4 0} \mathrm{ml} / \mathrm{min}\end{array}$ & $\begin{array}{l}\text { Very small graft (to left anterior descending } \\
\text { coronary artery), distal stenosis } \\
\text { Good flow } \\
\text { Good flow }\end{array}$ \\
\hline
\end{tabular}



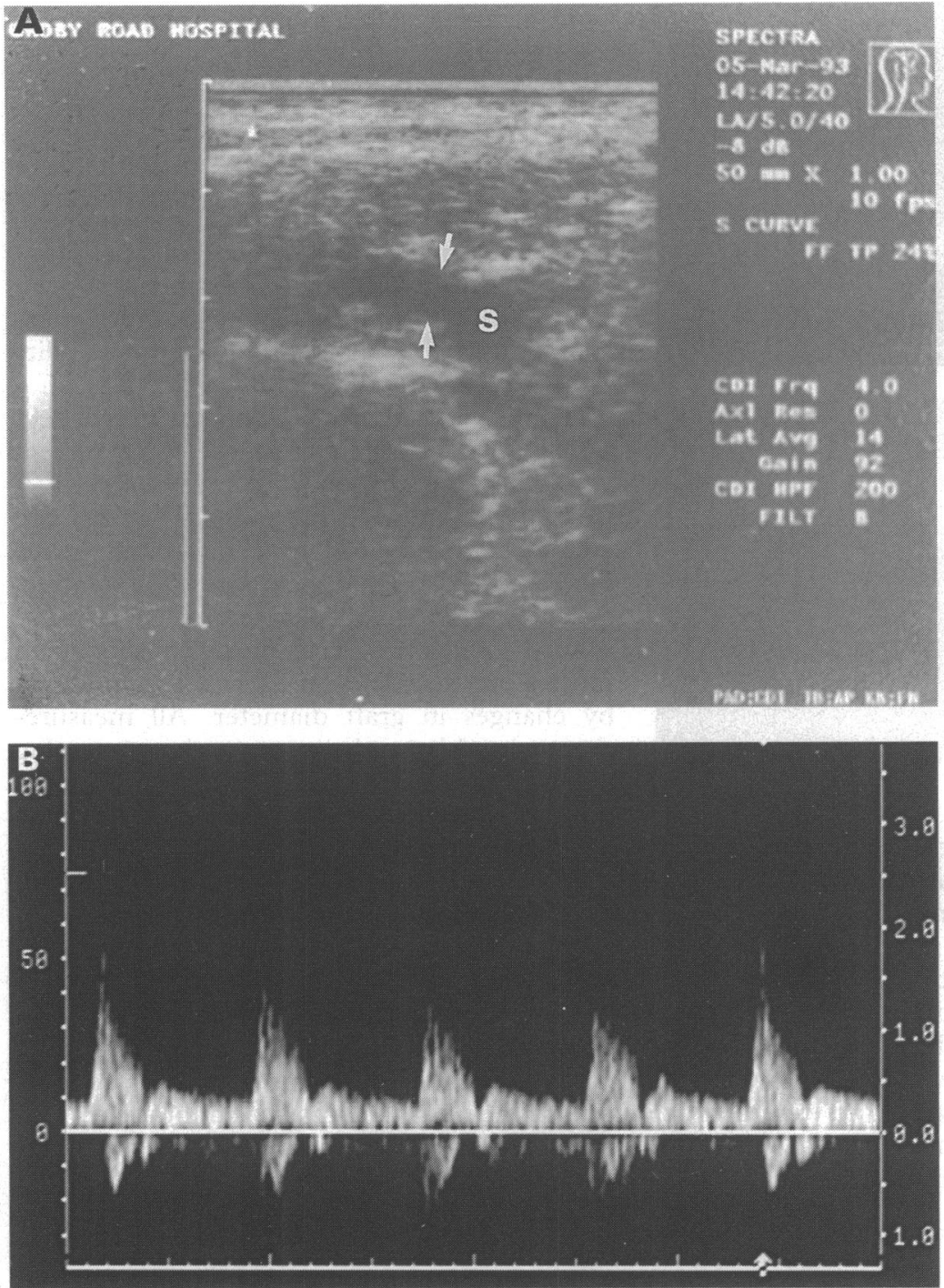

Figure 3 (A) Two dimensional echocardiogram of the origin of the internal thoracic artery (arrows) from the subclavian artery (s) in case 1. (B) Doppler sonogram of proximal internal thoracic artery in case 1. There is a decreased systolic peak and little diastolic flow.

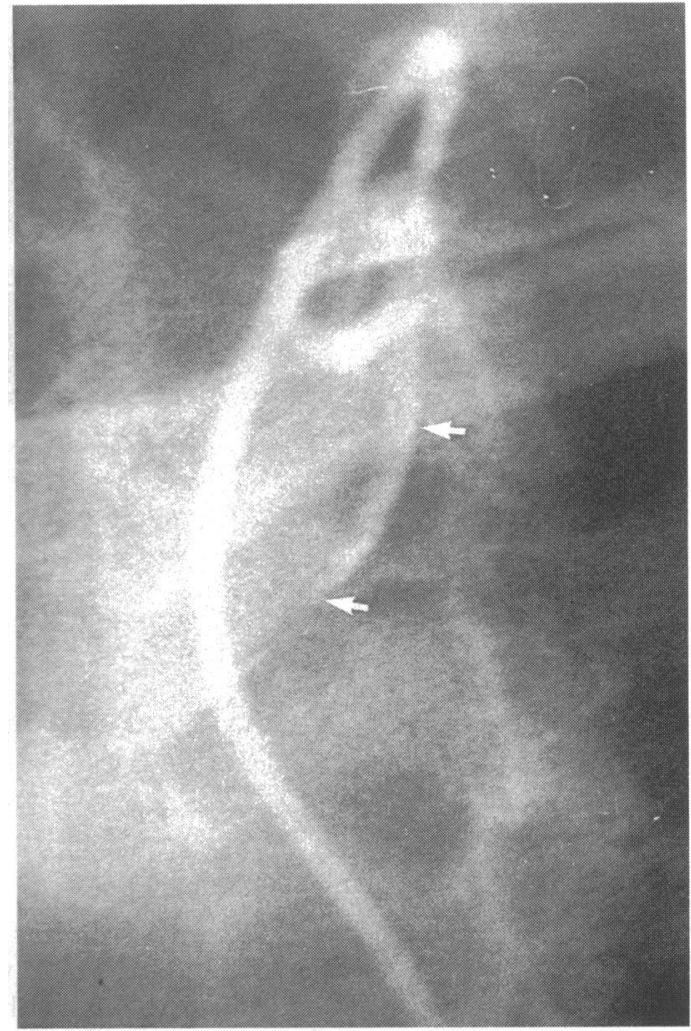

Figure 4 Angiogram of the origin of the grafted internal thoracic artery in case 1 . The internal thoracic artery is indicated by arrows. It is of good calibre proximally, but narrows abruptly at the level of the second arrow.

part of the left internal thoracic artery was readily imaged (fig $3 \mathrm{~A}$ ) and was about $3 \mathrm{~mm}$ in diameter. The Doppler sonogram was abnormal, showing a systolic peak with some turbulence and flow reversal and little diastolic flow (systolic to diastolic peak velocity ratio $4 \cdot 2$ ) (fig 3B). At angiography (fig 4), the stump of the internal thoracic artery was patent and supplied an anterior intercostal vessel. Subsequently, however, the graft was completely occluded. The proximal native left anterior descending coronary artery was completely occluded, with minor prograde collateral filling of distal vessels in this territory. The saphenous vein graft to the right coronary artery was patent; that to the obtuse marginal branch was occluded. Angioplasty was undertaken to a stenosis in the obtuse marginal branch of the circumflex coronary artery.

\section{CASE 2}

The patient was a 57 year old man (patient J). He had internal mammary grafting in February 1992. Angina recurred three months after grafting and angiography showed a small calibre left internal thoracic artery graft with poor flow but no obvious stenosis. Angioplasty was attempted to the proximal left anterior descending artery. Six weeks after angioplasty he still reported angina and an exercise test was positive at stage 3 of the Bruce protocol with anterior ST depression. Duplex ultrasound examination was carried out at this stage. It showed a Ultrasound examination of the internal thoracic artery was undertaken, followed by repeat coronary angiography. The proximal 
Figure 5 (A) Doppler sonogram of internal thoracic artery in case 2. Note decreased systolic and diastolic flow. (B) Angiogram of the subclavian artery in case 2. A small calibre internal thoracic artery is shown by the arrows. It could not be selectively cannulated.
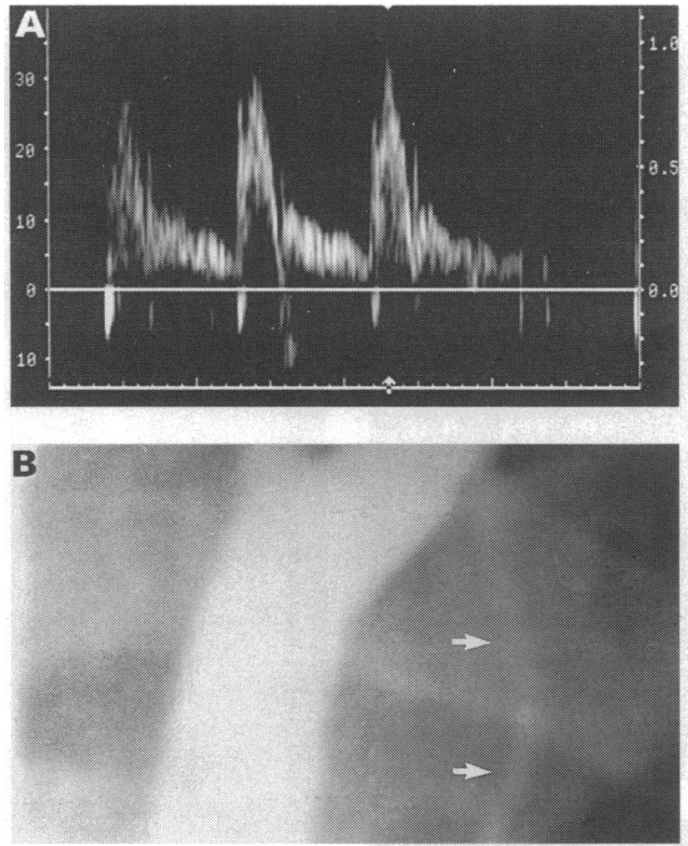

small, $2 \mathrm{~mm}$ diameter graft which was located with difficulty. There was a biphasic flow pattern (fig 5A), but with much decreased flow. Calculated systolic flow was $7.8 \mathrm{ml} / \mathrm{min}$, diastolic flow $7.2 \mathrm{ml} / \mathrm{min}$, total flow $15 \mathrm{ml} / \mathrm{min}$, and peak systolic/peak diastolic velocity ratio $1 \cdot 82$. Repeat angiography showed restenosis at the site of angioplasty and poor flow in the graft (fig 5B). Repeat ultrasound examination one year later (March 1993) showed no change in the flow pattern in the graft.

\section{Discussion}

A normally functioning internal thoracic artery graft shows a characteristic biphasic flow pattern in its proximal part (fig 1). We have previously suggested ${ }^{4}$ that the systolic phase is caused by blood flow distending the graft (and running off into any persisting intercostal connections) at a time of high intramyocardial resistance, and diastolic flow occurs when intramyocardial resistance decreases during diastole. Time averaged velocity is the variable most directly related to changes in graft flow, but where facilities for measuring it are not available, flow can be estimated from systolic and diastolic peak velocities. We have shown elsewhere (Mauric $\mathrm{A}$, de Bono $\mathrm{D}$, unpublished data) that the systolic to diastolic peak velocity ratio and systolic to diastolic flow ratios can vary in individual patients with exercise, blood pressure, and vasodilatation. In this study there was a positive correlation between total flow and peak systolic and peak diastolic flow. This is to be expected in a normally functioning graft as a large systolic flow component would be expected to indicate a large volume, compliant graft, and a large diastolic component with free runoff into the coronary vessels. As discussed in the following paragraphs, graft obstruction or poor runoff is often associated with the preservation of systolic but reduction of diastolic flow.
Imaging ungrafted internal thoracic arteries is relatively easy, but imaging grafted vessels is more difficult and there is a definite "learning curve"-the $84 \%$ of grafted vessels imaged in the last 50 patients is probably close to the best which can be achieved, and the graft was imaged in $75 \%$ of patients with ischaemic symptoms. The two principal problems in the quantitative assessment of graft flow are the inherent inaccuracies in the measurement of graft diameter and the possibility of underestimating blood flow velocity.

Time averaged velocity and graft cross sectional area contributed to the inter patient variability of graft flow which we observed. It is well recognised that arterial grafts can adapt to increased flow velocity and hence increased endothelial shear stress, by dilating, and hence we might expect to see a trend towards a constant maximum velocity, with further increases in graft flow accommodated by changes in graft diameter. All measurements in this study were made on resting patients, and a resting velocity close to maximum might indicate a limited reserve of flow for increased demand during exercise.

Distal graft obstruction or occlusion will decrease or abolish the diastolic flow component, as illustrated in case 1, and in our experience this has been a consistent finding in patients with graft obstruction, as also observed by Takagi et al. ${ }^{9}$ The continuing patency of the graft in this patient is probably due to the persisting intercostal branches and the flow pattern is similar to that we have previously described in the non-grafted internal thoracic artery. It is uncertain whether the cause of graft failure in case 1 was related to poor runoff into the endarterectomised vessel, or to damage to the internal thoracic artery at the time of previous radiotherapy.

Systolic flow may be preserved as in case 1, but it is often reduced in parallel with diastolic flow and graft diameter (case 2). This could be caused by limited runoff, by the failure of graft dilatation in the presence of good distal runoff as a consequence of graft damage, or by competition from increased proximal flow. The combination of poor graft flow and persisting ischaemia would suggest graft inadequacy rather than competitive flow. We have seen a number of patients with apparently poor graft flow who had no evidence of myocardial ischaemia. In some of these patients it is likely that there was competitive flow from the proximal left anterior descending vessel; in others it is likely that the graft was supplying a region containing little viable myocardium.

Small calibre grafts are more difficult to image; in one patient a right internal thoracic artery graft to the left anterior descending coronary artery became much easier to image when a distal stenosis was relieved by angioplasty (table 2). If a graft cannot be imaged at all it is not possible to draw any inferences about its patency from the ultrasound studies: two patients had widely patent grafts on angiography which could not be imaged using ultrasound. On the other hand, in every 
patient in whom a graft was imaged and the patient subsequently underwent angiography the assessment of graft function by ultrasound was confirmed angiographically.

\section{Conclusion}

Trancutaneous duplex ultrasound is a useful and practicable method for following up patients with internal thoracic artery to coronary artery bypass grafts. Demonstration of a normal flow pattern with good graft flow makes graft dysfunction unlikely, although progression of native vessel disease is not excluded. The combination of ischaemic symptoms with either an abnormal flow pattern or graft flow in the lowest quartile suggests graft malfunction or poor runoff. No conclusions can be drawn if the graft cannot be imaged.

This work was supported by a grant from the British Heart Foundation. The technical assistance of Brenda Lawry is gratefully acknowledged.
1 Lytle BW, Loop FD, Thurer RL, et al. Isolated left anterior descending coronary atherosclerosis: long term
comparison of internal mammary artery and venous comparison of internal mammary art

2 Cosgrove DM, Loop FD, Lytle BW, et al. Determinants of 10 year survival after primary myocardial revascularisation. Ann Thorac Surg 1985;202:480-90.

3 Cameron A, Kemp HG Jr, Green GE. Bypass surgery with the internal mammary artery graft: 15 year follow up. Circulation 1986;74(suppl III) 30-6.

4 de Bono DP, Samani NJ, Spyt TJ, Hartshorne T, Thrush AJ, Evans DH. Transcutaneous ultrasound measurement of bloodflow in internal mammary artery to coronary artery grafts. Lancet 1992;339:379-81.

5 de Bono DP. Ultrasound measurement of blood flow in internal mammary artery grafts. In: Turina $M$, Luescher $\mathrm{T}$, eds. Coronary artery Grafting. Geneva: Springer Verlag, 1994.

6 Fusejima K, Takahara Y, Sudo Y, Murayama H, Masuda $\mathrm{Y}$, Inagaki $\mathrm{Y}$. Comparison of coronary haemodynamics in patients with internal mammary artery and saphenous vein coronary artery bypass grafts: a non invasive approach using combined two dimensional and Doppler echocardiography. $\mathcal{F}$ Am Coll Cardiol 1990;15:131-9.

7 Krijne R, Lyttwin RM, Holtgren R, Heinrich KW, Marx $\mathbf{R}$, Sons H. Combined two dimensional and Doppler sonographic examination of internal mammary grafts from the supraclavicular fossa. Int $\mathcal{f}$ Cardiol 1992; 37:61-4.

8 van Son JAM, Skotnicki SH, Peters MB, Pijls NH, Noyez $L$, van Asten WN. Non-invasive hemodynamic assessment of the internal mammary artery in myocardial ment of the internal mammary artery in myoc

9 Takagi T, Yoshikawa J, Yoshida K, Akasaka T. Takagi T, Yoshikawa J, Yoshida K, Akasaka T. patency using duplex Doppler echocardiography from patency using duplex Doppler echocardiography from 1647-52. 